\title{
A Rational Use of Clozapine Based on Adverse Drug Reactions, Pharmacokinetics, and Clinical Pharmacopsychology
}

\author{
Jose de Leon ${ }^{\mathrm{a}-\mathrm{c}}$ Can-Jun Ruan ${ }^{\mathrm{d}, \mathrm{e}}$ Georgios Schoretsanitis ${ }^{f}$ \\ Carlos De las Cuevas 9
}

\begin{abstract}
${ }^{a}$ Mental Health Research Center at Eastern State Hospital, Lexington, KY, USA; b Psychiatry and Neurosciences Research Group (CTS-549), Institute of Neurosciences, University of Granada, Granada, Spain; 'Biomedical Research Centre in Mental Health Net (CIBERSAM), Santiago Apóstol Hospital, University of the Basque Country, Vitoria, Spain; ${ }^{d}$ The National Clinical Research Centre for Mental Disorders, Beijing Key Laboratory of Mental Disorders, and Laboratory of Clinical Psychopharmacology, Beijing Anding Hospital, Capital Medical University, Beijing, China; eAdvanced Innovation Center for Human Brain Protection, Capital Medical University, Beijing, China; ${ }^{\mathrm{f}}$ Department of Psychiatry, Zucker Hillside Hospital, Northwell Health, Glen Oaks, NY, USA; 9 Department of Internal Medicine, Dermatology and Psychiatry, University of La Laguna, San Cristóbal de La Laguna, Spain
\end{abstract}

\section{Keywords}

Asian continental ancestry group/genetics · Clozapine/ adverse effects · Clozapine, blood · Clozapine/metabolism . Clozapine/toxicity · COVID-19 · Drug labeling · Infection · Inflammation · Mortality/drug effects

\begin{abstract}
Using Richardson and Davidson's model and the sciences of pharmacokinetics and clinical pharmacopsychology, this article reviewed the: (1) poor life expectancy associated with treatment-resistant schizophrenia (TRS), which may be improved in patients who adhere to clozapine; (2) findings that clozapine is the best treatment for TRS (according to efficacy, effectiveness and well-being); and (3) potential for clozapine to cause vulnerabilities, including potentially lethal adverse drug reactions such as agranulocytosis, pneumonia, and myocarditis. Rational use requires: (1) modification of the clozapine package insert worldwide to include lower doses
\end{abstract}

for Asians and to avoid the lethality associated with pneumonia, (2) the use of clozapine levels for personalizing dosing, and (3) the use of slow and personalized titration. This may make clozapine as safe as possible and contribute to increased life expectancy and well-being. In the absence of data on COVID-19 in clozapine patients, clozapine possibly impairs immunological mechanisms and may increase pneumonia risk in infected patients. Psychiatrists should call their clozapine patients and families and explain to them that if the patient develops fever or flu-like symptoms, the psychiatrist should be called and should consider halving the clozapine dose. If the patient is hospitalized with pneumonia, the treating physician needs to assess for symptoms of clozapine intoxication since halving the dose may not be enough for all patients; consider decreasing it to one-third or even stopping it. Once the signs of inflammation and fever have disappeared, the clozapine dose can be slowly increased to the prior dosage level.

(c) 2020 S. Karger AG, Base karger@karger.com

(C) 2020 S. Karger AG, Basel

www.karger.com/pps

Karger ${ }^{\prime}=$
Jose de Leon, MD

University of Kentucky Mental Health Research Center at Eastern State Hospital 1350 Bull Lea Road

Lexington, KY 40511 (USA)

jdeleon@uky.edu 
Psychiatric textbooks and article reviews in psychiatric journals ignore the recent scientific advances on the mechanism of adverse drug reactions (ADRs), pharmacokinetics, and clinical pharmacopsychology which are the basis for this article review on the rational use of clozapine for treatment-resistant schizophrenia (TRS).

In an editorial, Fava [1] first used the scheme of Richardson and Doster [2] to propose a rational use of antidepressants. Richardson and Doster [2] proposed that, in evidence-based medical decision-making for individual patients, three dimensions should be considered: (1) baseline risk of poor outcomes from an index disorder that is not treated, (2) responsiveness to the treatment option, and (3) vulnerability to ADRs. This approach is similar to the World Health Organization's (WHO) approach, which characterizes the rational use of medicine as, "Patients receive medications appropriate to their clinical needs, in doses that meet their own individual requirements, for an adequate period of time, and at the lowest cost to them and their community" [3].

This review first introduces the recent advances on ADRs, pharmacokinetics and clinical pharmacopsychology regarding clozapine. After this introduction, the following three sections apply Richardson and Doster's model to TRS, the main clozapine indication. Then the current use of clozapine is reviewed, and a new rational approach is proposed with our current recommendations regarding the COVID-19 infections. The last two sections of this review describe the technological advances that may influence future clozapine use and other clozapine indications.

\section{ADRs and Clozapine}

There are two major classes of ADRs: (1) unpredictable, uncommon and idiosyncratic, and (2) predictable, common and dose-related [4]. The latter are better described as related to serum concentrations [5]. There is recent agreement among the most important medical scientists, such as Vanderbroucke and Psaty [6] or Ioannidis [7], that the status of ADR science is highly deficient. According to them, there are two main reasons for the poor status of ADR knowledge [6, 7]: (1) pharmaceutical companies tend to try to minimize the existence of ADRs, and (2) rare but potentially lethal ADRs, usually idiosyncratic, are usually not detected by the randomized clinical trials (RCTs) required for drug approval, since they are shortterm and include only a few thousand patients. These deficiencies have led to several drugs being withdrawn from the market due to unidentified potentially lethal ADRs [8].

On the other hand, psychiatric textbooks and review articles call ADRs "side effects" and do not explain these two classes of limitations in the field. Similarly, recent review articles [9-11] stressed that clozapine is prone to cause ADRs but do not explain these advances in knowledge of ADRs.

\section{Pharmacokinetic Introduction to the Rational Use of Clozapine in TRS}

A rational clozapine treatment needs first to be based on clozapine pharmacokinetics, which is a major determinant in clozapine dosing. Clozapine depends on the cytochrome P450 1A2 (CYP1A2) for its metabolism and follows pharmacokinetic changes similar to other CYP$1 \mathrm{~A} 2$ drugs. This is not clearly explained in the US package insert. Online supplementary Box S1 (see www. karger.com/doi/10.1159/000507638 for all online suppl. material) [12-50] provides a critical chronology of the protracted history of the pharmacokinetics of clozapine, and the contributions of two other CYP1A2 drugs, theophylline and caffeine, to its understanding. The inhibitory effects of infections on CYP1A2 were first described in theophylline $[15,18,19]$ and 25 years later replicated in clozapine. In 1997, two studies ignored by Western clozapine researchers stated that Chinese have lower clozapine metabolism than Caucasians [24, 25]. Then, 20 years later, a well-controlled study using caffeine demonstrated that East Asians have lower CYP1A2 activity [34]. It is now clear that all Asians have lower clozapine metabolism and need half the clozapine dosage used in the US [45-48].

Measuring serum clozapine levels, called therapeutic drug monitoring (TDM) by pharmacologists, is the cornerstone for the rational use of clozapine personalized dosing since a minimum serum level of $350 \mathrm{ng} / \mathrm{mL}$ is needed for clozapine response [51]. Pharmacokinetic science has determined that, in therapeutic dosages, clozapine follows linear kinetics (the relationship between dose and concentration is linear) and provides information on which variables influence clozapine clearance from the body and, therefore, clozapine dosing. The most important clozapine metabolite is norclozapine; clozapine-N-oxide is second. Norclozapine, clozapine-N-oxide, and other hydrosoluble metabolites are then eliminated by the kidney.

Clozapine clearance is measured by the concentrationto-dose (C/D) ratio. Online supplementary Box S2 [5, 44- 
$46,48,52-67]$ describes the important pharmacokinetic variables for clozapine clearance. Higher clozapine C/D ratios, indicating lower clearance, are associated with females, non-smokers, Asians, genetic poor metabolizers, inhibitors, obesity, inflammation, and possibly with renal impairment and pregnancy. Lower clozapine C/D ratios indicate lack of adherence or higher clearance associated with males, smokers, non-Asians, and inducers.

Two prior TDM review articles $[68,69]$ are summarized in online supplementary Box S3 [31, 44, 50, 51, 55, 58-61, 63, 65, 68-91] which also describe our extensive experience with thousands of inpatient clozapine TDMs under standard conditions (trough and steady-state levels) in the US [44] and China [45, 65]. Many of these inpatients were followed for months and/or years after changes in important pharmacokinetic variables [31, 44, 50, 58-61, 63, 65, 74, 79, 86-91].

Published review articles [92-94] usually insist on the wide variability of clozapine TDM among individuals and the difficulty of interpreting a single clozapine level, but they fail to pay attention to findings from these two sciences: pharmacokinetics and clinical pharmacopsychology, which help in interpreting variability in clozapine levels. In inpatients, repeated measures allow the calculation of average clozapine clearance in an individual through a mean clozapine C/D ratio, which can be compared using dose-correction factors after changes in important pharmacokinetic variables (e.g., before and after use of an inhibitor).

\section{Introduction of Clinical Pharmacopsychology in the Rational Use of Clozapine in TRS}

When dealing with TDM in outpatients, one cannot ignore lack of adherence as a major problem in many clozapine outpatients, frequently leading to hospitalizations [95-99]. This is not surprising to the authors, who are interested in aiding the development of the science of clinical pharmacopsychology [100]. Lack of adherence is a major issue in treatment maintenance in psychiatry $[101,102]$, and when analyzing outpatient samples, a low clozapine $\mathrm{C} / \mathrm{D}$ ratio is almost never explained by the patient being a genetic ultrarapid metabolizer and rarely explained by co-prescription of a potent inducer; it is almost always explained by lack of adherence [46, 54, 87]. Unfortunately, experts who write reviews on clozapine TDM do not consider the major relevance of lack of adherence in clozapine outpatients. Clinicians do not appear to be free of this bias and seem to think that lack of adherence may be a problem for other patients, but their own patients are adherent. TDM results demonstrate that one-third to one-half of the patients considered TRS patients by their psychiatrists are simply not taking their antipsychotics $[103,104]$. Unfortunately, no clozapine studies explored the pharmacopsychological variables influencing poor adherence. Based on the pattern of lack of adherence in psychiatric patients, one can hypothesize that each non-adherent clozapine patient may be influenced by one or more factors such as lack of insight about the illness, self-reported attitudes related to their history of medication exposure, or personality style related to feelings of control [105]. Addressing specific pharmacopsychological variables in each non-adherent patient has the potential to improve clozapine adherence.

\section{Baseline Risk of Poor Outcomes from TRS without Treatment}

The literature usually describes approximately onethird of schizophrenia patients as treatment-resistant, but the TRS definitions vary from study to study [106]. On the other hand, the literature agrees that: (1) clozapine is the most effective treatment for these patients $[107,108]$ and (2) among schizophrenia patients, those with treatment-resistant forms have the more obvious abnormalities in brain imaging $[109,110]$, and are those associated with greater individual and societal burden [111].

To better understand the benefits and risks of clozapine in TRS, one would like to know the effects of TRS on life expectancy and how it is modified by clozapine or other antipsychotics; however, only data on schizophrenia in general is available. In a meta-analysis [112], schizophrenia was associated with a weighted average of 14.5 years of potential life lost. In a recent Swedish cohort with $>20,000$ patients, the cumulative antipsychotic exposure displays a U-shaped curve for overall mortality with no antipsychotic exposure having the worst outcome [113]. Regarding clozapine, in a meta-analysis of 24 studies with long-term follow-up of treatment, Vermeulen et al. [114] found long-term, crude mortality rate ratios were significantly lower in patients continuously treated with clozapine compared to patients treated with other antipsychotics (mortality rate ratio $=0.56$ ). Online supplementary Box S4 [112-116] describes two additional studies published after the meta-analysis, also showing lower mortality in clozapine patients $[115,116]$. 


\section{Responsiveness to Clozapine in TRS}

Online supplementary Box S5 describes in detail what we know regarding clozapine responsiveness measured by efficacy, effectiveness and well-being.

\section{Efficacy: RCTs and Meta-Analysis}

RCTs tend to be of relatively short duration, are biased against including the most severe patients in psychiatry [117] and are, therefore, far from ideal in assessing response in TRS. Later, RCTs are combined in meta-analyses, which Feinstein called "statistical alchemy for the 21st century" [118]. The most complex meta-analysis, the network meta-analysis, compares drugs indirectly, and these comparisons are particularly problematic when there is no similarity in the RCTs [119].

In a TRS meta-analysis, Siskind et al. [120,121] found clozapine superiority. On the other hand, another research group using network meta-analyses published two articles; one by Samara et al. [122] found no clozapine superiority in TRS, but the other one by Huhn et al. [123] found that clozapine was the best antipsychotic for the acute treatment of multiple-episode schizophrenia in general. Not surprisingly, this TRS network metaanalysis by Samara et al. [122] has been criticized by lack of representativeness of the included RCTs [107, 124, 125].

\section{Effectiveness}

If one takes a more comprehensive view of what is important in clinical practice [126], and considers effectiveness based on two systematic reviews of naturalistic cohort studies [127, 128], clozapine was superior to other antipsychotics in decreasing discontinuation and decreasing hospitalization.

\section{Clozapine and Well-Being}

The importance of well-being during pharmacotherapy is receiving more and more attention [129] and is particularly relevant in explaining the high adherence of some patients to clozapine, demonstrated by the lower discontinuation rates in cohort studies [127, 128]. Clozapine positive effects on well-being in some patients may be influenced by clozapine effects on extrapyramidal symptoms [130-142], hostility [143, 144] and the "awakening" phenomenon [145-147] (online suppl. Box S5, section 3$)$.

\section{Vulnerability to ADRs and Prevention}

\section{Clozapine-Induced Agranulocytosis}

The description of clozapine-induced agranulocytosis in 1975 [14] derailed its widespread use around the world (online suppl. Box S1). The next step was the marketing of clozapine in the US in 1990 [12] with the requirement of weekly white cell blood counts (WBC) and a manufacturer-managed database. Then clozapine was progressively marketed in multiple countries with different levels of WBC monitoring [148]. In the US in 2015 [41], the WBC requirements were modified, returning to a unified WBC database and allowing for lower levels of absolute neutrophil count (ANC) for starting patients with benign ethnic neutropenia, as had previously been done in the UK $[149,150]$. Clinicians worldwide need to follow the respective regulations of their countries regarding WBC and ANC monitoring. Currently, agranulocytosis appears to be a well-managed risk. The WHO's database, VigiBase, has received reports on ADRs since 1968 from 134 drug agencies in countries around the world. Our VigiBase search on July 15, 2019, identified a $2 \%$ rate of fatal outcomes $(550 / 34,931)$ due to agranulocytosis since the onset of clozapine use [49]. Online supplementary Box S6 [49, 151-155] reviews our current knowledge of clozapine-induced agranulocytosis.

\section{Pneumonia}

The convergence of two historical findings (online suppl. Box S1) has finally led to the recent realization of the relevance of the association between clozapine and pneumonia and its lethality. The first historical finding was that inflammation releases cytokines that decrease the expression and activity of CYP1A2 with the potential of causing intoxication by CYP1A2 drugs. This was first demonstrated in theophylline $[15,18,19]$ and then 25 years later in clozapine [30,31]. Elevation of c-reactive protein (CRP) is a good marker that cytokines are being released, and that this may increase clozapine levels [156]. The second historical finding is that in 2005, the FDA modified the package insert of all second-generation antipsychotics to include a warning about death by pneumonia in patients with dementia [32]. Despite the fact that clozapine is not indicated for dementia, its package insert was modified, too. The association between clozapine and pneumonia is supported by data from the Taiwan registry [37], other studies previously reviewed [49], and further verified by a mirror-image study in the Danish registry [157].

More concerning is that pneumonia can be highly lethal in clozapine patients and is one of the most impor- 
tant causes of mortality in clozapine patients. This has been suggested by observational studies in the US [88, 158], the UK [159, 160], and Denmark [42]. Moreover, a VigiBase search [49] exploring pneumonia lethality in clozapine patients led to very concerning results: (1) 2,077 fatal outcomes (approximately four times higher than those associated with agranulocytosis), and (2) relatively high lethality of $30 \%$ (much higher than the $2 \%$ of agranulocytosis). Moreover, pneumonia was much more strongly associated with clozapine than the 3 most frequently prescribed second-generation antipsychotics; each of them had around 1/10 of the fatal outcomes of clozapine [161]. The lethality of pneumonia in clozapine patients is explained in that clozapine can contribute to pneumonia, and once pneumonia develops it can cause a clozapine intoxication; therefore, the combination of pneumonia and clozapine intoxication is highly lethal. This complex bidirectional association [162] is described in detail in online supplementary Box S7 [157, 163-169]. Our recommendations for decreasing the risk and lethality of pneumonia in clozapine patients are described in online supplementary Box S8 [65, 162, 170, 171]. The context for the clinical relevance of these recommendations is that pneumonia may be the most significant lifethreatening medical event connected with antipsychotic use [172].

\section{Myocarditis}

The controversy of clozapine-induced myocarditis is defined by two extreme positions first delineated in 2012 by Cohen et al. [35]. Australian experts think that with adequate monitoring clozapine-induced myocarditis is present in 3\% of patients, and those who do not find an incidence of 3\% among their patients are ignoring many cases [38]. The position of most clozapine experts in continental Europe is that clozapine-induced myocarditis is very rare. In the Danish registry, Rohde et al. [42] found an incidence of $0.03 \%$ and no fatal cases. If we assume that Danish clinicians do not know how to diagnose myocarditis and that they are missing 3\% of cases with a mortality rate of $6 \%$, the study by Rohde et al. [42], should have identified 6 deaths associated with clozapine-induced myocarditis instead of no deaths [162].

A recent meta-analysis of clozapine-induced myocarditis provides estimations for these two positions by describing an event rate of $2 \%$ in 9 Australian samples and of $0.3 \%$ in 15 non-Australian samples [173]. This metaanalysis provided no reason for this roughly 10 -fold difference between Australia and other countries.
Online supplementary Box S9 [38, 66, 162, 174-179] describes our model of clozapine-induced myocarditis as a hypersensitivity reaction similar to when rapid titrations of lamotrigine induce Stevens-Johnson syndrome and how to prevent it. Online supplementary Box S10 [16, $21,26,27,33,36,45,46,48,50,54,58,69,87,180-187]$ further describes the published data supporting this model in which rapid clozapine titration is key to explaining clozapine-induced myocarditis. Any titration that is too fast for a specific patient can cause clozapine-induced myocarditis or, more correctly, any kind of clozapine-induced inflammation [66]. Our most important recommendation is to always use slow and personalized clozapine titration (online suppl. Table S2) and weekly CRP (online suppl. Box S9).

\section{Other Potentially Lethal Clozapine ADRs}

Online supplementary Box S11 [49, 68, 188-207] explains that our VigiBase search [49] provided another four definitive clozapine ADRs associated with fatal outcomes: (1) constipation, (2) arrythmia, (3) seizures, and (4) syncope.

Clozapine is one of the antipsychotics most strongly associated with weight gain, hyperglycemia, and hyperlipidemia $[208,209]$. In a systematic review of cohort studies, clozapine was also associated with higher cardiometabolic-related risk outcomes [128]. As described before, clozapine is associated with longer survival [114]; it appears that its positive effects may outweigh its metabolic risks.

\section{Behavioral ADRs}

Behavioral ADRs secondary to psychiatric medications have not received enough attention $[131,132]$ and one of the best examples is clozapine-induced severe obsessive-compulsive symptoms (OCS). Due to its complexity and lack of good studies, there is no agreement in the literature on its management. In this journal issue, Kim et al. [210] reviewed the limited available literature and provided the very helpful conclusion that adding aripiprazole with/without clozapine dose reduction may be a good alternative to antidepressants for managing clozapine-associated OCS. Future controlled studies will need to clarify whether this conclusion is correct or not.

Clozapine is the second-generation antipsychotic most consistently associated with withdrawal symptoms [211]. Thus, clinicians should warn patients not to stop clozapine suddenly, since it has been associated with several withdrawal syndromes including: (1) cholinergic re- 
bound (including nausea, vomiting, diarrhea, headache, agitation, confusion, and diaphoresis) [212], (2) worsening psychosis and/or abnormal movements [213], and (3) even catatonic symptoms in patients who never had catatonia before [91]. When clozapine needs to be stopped suddenly due to serious ADRs, temporary treatment with anticholinergics with slow titration over 2-3 weeks may be a good option for preventing cholinergic rebound [212] and olanzapine may be a reasonable choice [214] for covering withdrawal from psychosis or abnormal movements. Although we do not recommend rapid titration in naïve patients, we have, on rare occasions, used it under very controlled inpatient conditions when previously known patients had severe withdrawal with psychotic exacerbations, or catatonia. These are extremely dangerous situations, and the sedating properties of clozapine can help as long as the patient is closely observed and the prior dosage needed to stabilize the patient and the level of tolerance are known.

A phenomenon even less well described in the literature is that some patients who have shown remarkable improvement in their psychosis and then stopped clozapine on their own never again recovered the dramatic response seen the first time $[215,216]$. Clinicians need to explain to any patient with dramatic response to clozapine that this may sometimes be lost by stopping clozapine.

\section{Contraindications}

In patients naïve to clozapine, the most important contraindication is the presence of some kind of myeloproliferative disorder or neutropenia that precludes having a high enough ANC required to start clozapine. Very rarely, patients can develop allergic reactions to clozapine and should not be exposed again. Most of the contraindications that a clinician faces are relative contraindications in which the risk of starting clozapine needs to be carefully balanced by including the patient and the family in the discussion regarding the risks, avoiding DDIs before starting clozapine as much as possible and stabilizing medical problems as much as possible [207]. In many patients, clozapine may be the last option after exhausting all other options with limited benefit.

\section{Current Use}

Most clozapine experts are concerned by the lack of use of clozapine worldwide, in spite of its benefit for TRS. An international study including 17 countries showed

Clozapine Use that in most countries clozapine use increased from 2005 to 2014. Nevertheless, great disparities were seen, with greatest use in Finland (189/100,000 persons) and New Zealand $(116 / 100,000)$, and least in the Japanese cohort $(0.6 / 100,000)$ and in the privately insured US cohort $(14 / 100,000)$ [217]. The term "clozaphobia," phobia of prescribers toward prescribing clozapine, has been proposed [218]. Online supplementary Box S12 describes barriers regarding clozapine use and successes in the Netherlands and New Zealand in increasing clozapine use [219-225].

\section{Proposal for More Rational Use of Clozapine}

A more rational use of clozapine is based on three pillars: (1) modification of the worldwide clozapine package insert reflecting the advances in clozapine pharmacokinetics, (2) the use of clozapine TDM to personalize clozapine dosing, and (3) the use of slow and personalized titration including CRP to avoid myocarditis and other clozapine-induced inflammations.

\section{Changing Worldwide Clozapine Package Inserts}

Clozapine package inserts worldwide should report that [47]: (1) Asians need half the dose prescribed in the US, (2) clinicians should be aware that pneumonia may be highly lethal in clozapine patients, and (3) clozapineinduced myocarditis during dose escalation can be reduced by slow personalized titration.

\section{The Best Way to Personalize Maintenance Dosing Is TDM if It Is Available}

TDM is recommended by the AGNP experts but is not mandatory in any country. In the opinion of the authors, the use of clozapine should become similar to the use of lithium, which requires TDM for dosing. Many countries do not have access to clozapine TDM; therefore, it is not reasonable to make TDM mandatory. However, ideally all countries should provide access to clozapine TDM; it is the best way of personalizing dosing since it reflects the combination of genetic, environmental and personal variables that influence dosing and the specific pharmacokinetics of each drug [5]. Moreover, due to clozapine ADRs and variability in dosing, clozapine TDM is costeffective [226].

Clozapine TDM is the best way to personalize the best maintenance dose to reach at least $350 \mathrm{ng} / \mathrm{ml}$ of serum clozapine concentrations [69]. To rule out lack of response, this clozapine dose should be maintained for 
enough time; some have proposed 3 months [106] and others, 8 weeks [227]. Prescribing the lowest dose that delivers therapeutic concentrations and efficacy will decrease the risk of clozapine ADRs and provide the safest baseline in case there are infections or inflammations in the future. Moreover, clozapine TDM helps to determine adherence of clozapine outpatients which may predict rehospitalization [95-99].

Psychiatrists with no access to clozapine TDM can use online supplementary Table S1, which shows the average clozapine dose recommended based on ethnicity, sex, smoking, and some DDIs. Due to difficulty in predicting clozapine dosage in patients taking fluvoxamine, as it is a potent inhibitor [55, 228], we do not recommend co-prescribing this drug with clozapine without TDM. As valproic acid can be an inhibitor of clozapine metabolism and an inducer of norclozapine metabolism, it is also better to avoid it [57].

\section{Slow and Personalized Titration with CRP Levels}

The Dutch clozapine guideline recommends slow titration with very slow titration for outpatients [223]. This may explain the lack of clozapine-induced myocarditis in the Netherlands. Therefore, there is little need for improving clozapine titration in the Netherlands.

In many other countries, personalized titration based on pharmacokinetic variables may be beneficial. Online supplementary Table S2 provides our recommendations for inpatient titrations and online supplementary Box S9 provides recommendations for preventing clozapine-induced myocarditis. Unfortunately, two unpredictable variables can make a patient behave as a clozapine poor metabolizer: genetics or undetected inflammations. To prevent those situations, our inpatient protocol recommends measuring CRP at the same time as WBC: at baseline and for the first 8 weeks of clozapine titration or until the final clozapine dose is reached. Measuring weekly CRP levels is much easier and less expensive than the intensive heart monitoring recommended by Australian experts [38, 178, 179]. Clozapine should not be started until CRP is normal, so that use of clozapine in patients with unidentified inflammations can be avoided. Subsequently, if the CRP is increased or the patient develops fever, this is a sign that the titration is too rapid for that patient, and the clozapine dose should not be further increased until CRP has normalized; this may prevent the progression of a clozapine-induced inflammation.

\section{COVID-19 Infections}

There is no data on COVID-19 in clozapine patients but, based on what we know about clozapine pharmacology, we can hypothesize that clozapine, possibly by impairing immunological mechanisms, may increase the risk of pneumonia in infected patients. More importantly, during this CODIV-19 epidemic, psychiatrists should call their clozapine patients and families and explain to them that if the patient develops fever or flu-like symptoms, they should call their psychiatrist, and if they cannot reach their psychiatrist, the patient should cut the clozapine dose in half. If the patient has to be admitted to a hospital due to COVID-19 pneumonia, the treating physician needs to assess for symptoms of clozapine intoxication since halving the dose may not be enough for all patients and consider decreasing it to one-third or even stopping it. Once the signs of inflammation and fever have disappeared, the clozapine dose can be slowly increased to the prior dosage level.

\section{Future Use: Technology Advances Coming to Market}

Online supplementary Box S13 [54, 155, 229-241] describes the recent commercialization and/or development of new technologies in pharmacogenetic testing, WBC monitoring, and TDM. The current commercial pharmacogenetic tests should not be used on clozapine patients. Currently, it is not clear whether the point of care devices providing WBC or TDM can facilitate clozapine prescription, or only make it more expensive. It is too early to decide whether some of the TDM technologies in development will provide easy and cheap ways to establish clozapine adherence.

\section{Other Clozapine Indications}

This review article focuses on the use of monotherapy clozapine for TRS, which is the main clozapine indication in the US and other countries [148, 242]. We do not know how clozapine changes the life expectancy of patients with other clozapine indications, enumerated in online supplementary Box S14 [29, 139-141, 148, 207, 242-257]. To decide to prescribe clozapine for any of these indications requires the psychiatrist to carefully balance, for each patient, the likelihood of responsiveness and vulnerabilities, remembering that data on responsiveness is limited. If the same clozapine doses for de Leon/Ruan/Schoretsanitis/

De las Cuevas 
TRS are used for other indications, the clozapine vulnerabilities and ADRs should be similar. In the experience of the authors, other indications, such as polydipsia or intellectual disability with self-injurious behaviors, may respond to lower clozapine doses and do not require reaching concentrations of $350 \mathrm{ng} / \mathrm{ml}$ to gain efficacy [207]. Clozapine dosing and TDM need to be explored by future studies focusing on these other indications. As clozapine may be a last resource for inpatients with extremely severe conditions besides TRS, for which providers have exhausted all other options, each patient with these other conditions should be considered on an individual basis after discussing it with the patient and the family.

Using Richardson and Davidson's model [2] and the sciences of pharmacokinetics and clinical pharmacopsychology, this article reviewed the: (1) poor life expectancy associated with TRS, which may be improved in patients who adhere to clozapine; (2) findings that clozapine is the best treatment for TRS (according to efficacy, effectiveness and well-being); and (3) potential for clozapine to cause vulnerabilities, including potentially lethal ADRs. Our proposal for rational use is based on three pillars: (1) modification of the clozapine package insert worldwide to reflect the advances in clozapine pharmacokinetics, (2) the use of clozapine TDM for personalizing clozapine dosing, and (3) the use of slow and personalized clozapine titrations. This proposal should make clozapine as safe as possible and may contribute to increasing the life expectancy of TRS patients taking clozapine and their well-being. Only time will tell whether this editorial accomplished its goal or further contributed to clozaphobia.

\section{Acknowledgments}

The authors thank Lorraine Maw, MA, for editorial assistance. Can-Jun Ruan is supported by a 2019 NARSAD Young Investigator Award from the Brain \& Behavior Research Foundation. The authors are grateful to the reviewers and editor who provided important suggestions for improving the article. Moreover, the first author is grateful to the multiple reviewers reviewing his clozapine articles published during 2019 and the first 3 months in 2020; some of their suggestions were also used in this article.

\section{Disclosure Statement}

This article received no support from any funding agency, commercial business, or not-for-profit institution. In the last 3 years, the authors have had no commercial conflicts of interest.

\section{Funding Sources}

None.

\section{Author Contributions}

J.d.L. wrote the first draft. All authors meet criteria for authorship and approved the final manuscript. Since 2015, J.d.L. and C.J.R. have studied $>3,500$ clozapine levels in Asians and reviewed the literature on clozapine levels regarding ethnic differences in metabolism and in inflammation in both Chinese and English languages. Since 2017, J.d.L. and G.S. have written articles developing a model for personalizing antipsychotic dosing using levels and focusing on drug-drug interactions. Since April of 2019, J.d.L. and C.D.C. have focused on the pharmacoepidemiology of clozapine adverse drug reactions.

\section{References}

1 Fava GA. Rational use of antidepressant drugs. Psychother Psychosom. 2014;83(4): 197-204.

2 Richardson WS, Doster LM. Comorbidity and multimorbidity need to be placed in the context of a framework of risk, responsiveness, and vulnerability. J Clin Epidemiol. 2014 Mar;67(3):244-6.

3 World Health Organization. Promoting Rational Use of Medicines: Core Components [Internet]. WHO Policy Perspectives on Medicines. Geneva: World Health Organization; 2002. p. 1-6 [accessed 2020 Feb 24]. http://archives.who.int/tbs/rational/h3011e. pdf

4 Aronson JK, Ferner RE. Clarification of terminology in drug safety. Drug Saf. 2005; 28(10):851-70.
5 de Leon J. Personalizing dosing of risperidone, paliperidone and clozapine using therapeutic drug monitoring and pharmacogenetics. Neuropharmacology. 2020 May; 168(107656): 107656.

6 Vandenbroucke JP, Psaty BM. Benefits and risks of drug treatments: how to combine the best evidence on benefits with the best data about adverse effects. JAMA. 2008 Nov; 300(20):2417-9.

7 Ioannidis JP. Adverse events in randomized trials: neglected, restricted, distorted, and silenced. Arch Intern Med. 2009 Oct;169(19): 1737-9.
8 Issa AM, Phillips KA, Van Bebber S, Nidamarthy HG, Lasser KE, Haas JS, et al. Drug withdrawals in the United States: a systematic review of the evidence and analysis of trends. Curr Drug Saf. 2007 Sep;2(3):177-85.

9 Citrome L, McEvoy JP, Saklad SR. Guide to the management of clozapine-related tolerability and safety concerns. Clin Schizophr Relat Psychoses. 2016;10(3):163-77.

10 Remington G, Lee J, Agid O, Takeuchi $\mathrm{H}$, Foussias G, Hahn M, et al. Clozapine's critical role in treatment resistant schizophrenia: ensuring both safety and use. Expert Opin Drug Saf. 2016 Sep;15(9):1193-203. 
11 De Berardis D, Rapini G, Olivieri L, Di Nicola D, Tomasetti C, Valchera A, et al. Safety of antipsychotics for the treatment of schizophrenia: a focus on the adverse effects of clozapine. Ther Adv Drug Saf. 2018 May;9(5): 237-56.

12 Crilly J. The history of clozapine and its emergence in the US market: a review and analysis. Hist Psychiatry. 2007 Mar;18(1):39-60.

13 Simpson GM, Varga E. Clozapine-a new antipsychotic agent. Curr Ther Res Clin Exp. 1974 Jul;16(7):679-86.

14 Idänpään-Heikkilä J, Alhava E, Olkinuora M, Palva I. Letter: clozapine and agranulocytosis. Lancet. 1975 Sep;2(7935):611.

15 Chang KC, Bell TD, Lauer BA, Chai H. Altered theophylline pharmacokinetics during acute respiratory viral illness. Lancet. 1978 May;1(8074):1132-3.

16 Vesterby A, Pedersen JH, Kaempe B, Thomsen NJ. [Sudden death during treatment with clozapine (Leponex)]. Ugeskr Laeger. 1980 Jan;142(3):170-1.

17 Kane J, Honigfeld G, Singer J, Meltzer H. Clozapine for the treatment-resistant schizophrenic. A double-blind comparison with chlorpromazine. Arch Gen Psychiatry. 1988 Sep;45(9):789-96.

18 Shilalukey K, Robieux I, Spino M, Greenwald M, Shear N, Koren G. Are current pediatric dose recommendations for intravenous theophylline appropriate? J Asthma. 1993;30(2): 109-21.

19 Abdel-Razzak Z, Loyer P, Fautrel A, Gautier JC, Corcos L, Turlin B, et al. Cytokines downregulate expression of major cytochrome $\mathrm{P}-450$ enzymes in adult human hepatocytes in primary culture. Mol Pharmacol. 1993 Oct; 44(4):707-15.

20 Bertilsson L, Carrillo JA, Dahl ML, Llerena A, Alm C, Bondesson U, et al. Clozapine disposition covaries with CYP1A2 activity determined by a caffeine test. Br J Clin Pharmacol. 1994 Nov;38(5):471-3.

21 Bandelow B, Degner D, Kreusch U, Rüther E. Myocarditis under therapy with clozapine. Schizophr Res. 1995 Nov;17(3):293-4.

22 Flockhart DA. Drug interactions, cardiac toxicity, and terfenadine: from bench to clinic? J Clin Psychopharmacol. 1996 Apr;16(2):101-3.

23 de Leon J. Highlights of drug package inserts and the website DailyMed: the need for further improvement in package inserts to help busy prescribers. J Clin Psychopharmacol. 2011 Jun;31(3):263-5.

24 Chang WH, Lin SK, Lane HY, Hu WH, Jann MW, Lin HN. Clozapine dosages and plasma drug concentrations. J Formos Med Assoc. 1997 Aug;96(8):599-605.

25 Chong SA, Tan CH, Khoo YM, Lee HS, Wong $\mathrm{KE}$, Ngui F, et al. Clinical evaluation and plasma clozapine concentrations in Chinese patients with schizophrenia. Ther Drug Monit. 1997 Apr;19(2):219-23.
26 Kilian JG, Kerr K, Lawrence C, Celermajer DS. Myocarditis and cardiomyopathy associated with clozapine. Lancet. 1999 Nov; 354(9193):1841-5.

27 Devarajan S, Kutcher SP, Dursun SM. Clozapine and sudden death. Lancet. 2000 Mar; 355(9206):841.

28 La Grenade L, Graham D, Trontell A. Myocarditis and cardiomyopathy associated with clozapine use in the United States. N Engl J Med. 2001 Jul;345(3):224-5.

29 Meltzer HY, Alphs L, Green AI, Altamura AC, Anand R, Bertoldi A, et al.; International Suicide Prevention Trial Study Group. Clozapine treatment for suicidality in schizophrenia: International Suicide Prevention Trial (InterSePT). Arch Gen Psychiatry. 2003 Jan;60(1):82-91.

30 Raaska K, Raitasuo V, Arstila M, Neuvonen PJ. Bacterial pneumonia can increase serum concentration of clozapine. Eur J Clin Pharmacol. 2002 Aug;58(5):321-2.

31 de Leon J, Diaz FJ. Serious respiratory infections can increase clozapine levels and contribute to side effects: a case report. Prog Neuropsychopharmacol Biol Psychiatry. 2003 Sep;27(6):1059-63.

32 US Food and Drug Administration. Public Health Advisory: Deaths with Antipsychotics in Elderly Patients with Behavioral Disturbances [Internet]. Silver Spring: FDA; 2005 [accessed 2020 Apr 3]. Available at: https://wayback.archive-it.org/7993/20170113112252/ http://www.fda.gov/Drugs/DrugSafety/PostmarketDrugSafetyInformationforPatientsandProviders/ucm053171.htm.

33 Berk M, Fitzsimons J, Lambert T, Pantelis C, Kulkarni J, Castle D, et al. Monitoring the safe use of clozapine: a consensus view from Victoria, Australia. CNS Drugs. 2007;21(2):11727.

34 Ghotbi R, Christensen M, Roh HK, Ingelman-Sundberg M, Aklillu E, Bertilsson L. Comparisons of CYP1A2 genetic polymorphisms, enzyme activity and the genotypephenotype relationship in Swedes and Koreans. Eur J Clin Pharmacol. 2007 Jun;63(6): 537-46.

35 Cohen D, Bogers JP, van Dijk D, Bakker B, Schulte PF. Beyond white blood cell monitoring: screening in the initial phase of clozapine therapy. J Clin Psychiatry. 2012 Oct;73(10): 1307-12.

36 Ronaldson KJ, Fitzgerald PB, Taylor AJ, Topliss DJ, Wolfe R, McNeil JJ. Rapid clozapine dose titration and concomitant sodium valproate increase the risk of myocarditis with clozapine: a case-control study. Schizophr Res. 2012 Nov; 141(2-3):173-8.

37 Kuo CJ, Yang SY, Liao YT, Chen WJ, Lee WC, Shau WY, et al. Second-generation antipsychotic medications and risk of pneumonia in schizophrenia. Schizophr Bull. 2013 May; 39(3):648-57.
38 Ronaldson KJ, Fitzgerald PB, McNeil JJ. Clozapine-induced myocarditis, a widely overlooked adverse reaction. Acta Psychiatr Scand. 2015 Oct;132(4):231-40.

39 Freudenreich O. Clozapine-induced myocarditis: prescribe safely but do prescribe. Acta Psychiatr Scand. 2015 Oct;132(4):240-1.

40 de Leon J, Tang YL, Baptista T, Cohen D, Schulte PF. Titrating clozapine amidst recommendations proposing high myocarditis risk and rapid titrations. Acta Psychiatr Scand. 2015 Oct;132(4):242-3.

41 US Food and Drug and Administration. FDA Modifies Monitoring for Neutropenia Associated with Schizophrenia Medicine Clozapine; Approves New Shared REMS Program for all Clozapine Medicines [Internet]. Silver Spring: FDA; 2015 [accessed 2015 Dec 21]. Available from: www.fda.gov/Drugs/DrugSafety/ucm 461853.htm

42 Rohde C, Polcwiartek C, Kragholm K, Ebdrup BH, Siskind D, Nielsen J. Adverse cardiac events in out-patients initiating clozapine treatment: a nationwide register-based study. Acta Psychiatr Scand. 2018 Jan;137(1):47-53.

43 Clark SR, Warren NS, Kim G, Jankowiak D, Schubert KO, Kisely S, et al. Elevated clozapine levels associated with infection: A systematic review. Schizophr Res. 2018 Feb;192: 50-6.

44 Diaz FJ, Josiassen RC, de Leon J. The effect of body weight changes on total plasma clozapine concentrations determined by applying a statistical model to the data from a doubleblind trial. J Clin Psychopharmacol. 2018 Oct; 38(5):442-6.

45 Ruan CJ, Zang YN, Wang CY, Cheng YH, Sun C, Spina E, et al. Clozapine metabolism in East Asians and Caucasians: a pilot exploration of the prevalence of poor metabolizers and a systematic review. J Clin Psychopharmacol. 2019 Mar/Apr;39(2):135-44.

46 Ruan CJ, Wang CY, Tang YL, Lin SK, Lee ST, Hong KS, et al. Exploring the prevalence of clozapine phenotypic poor metabolizers in 4 Asian samples: they ranged between $2 \%$ and 13. J Clin Psychopharmacol. 2019 Nov/Dec; 39(6):644-8.

47 de Leon J, Ruan CJ, Schoretsanitis G, Kane JM. Dose and safety concerns of clozapine: worldwide package inserts need revisions. Schizophr Res. 2020 Jan 8;pii: S09209964(19)30579-1.

48 de Leon J, Rajkumar AP, Kaithi AR, Schoretsanitis G, Kane JM, Wang CY, et al. Do Asian patients require only half of the clozapine dose prescribed for Caucasians? A critical overview. Indian J Psychol Med. 2020 Jan; 42(1):4-10

49 De Leon J, Sanz EJ, De Las Cuevas C. Data from the World Health Organization's pharmacovigilance database supports the prominent role of pneumonia in mortality associated with clozapine adverse drug reactions. Schizophr Bull. 2020 Jan;46(1):1-3. 
50 de Leon J, Rhee DW, Kondracke A, DiuguidGerber J. Rapid titration and decreased clozapine clearance may help explain five cases of clozapine-induced myocarditis in a New York hospital. Psychosomatics. 2020 Jan Feb;61(1):102-3.

51 Hiemke C, Bergemann N, Clement HW, Conca A, Deckert J, Domschke K, et al. Consensus Guidelines for Therapeutic Drug Monitoring in Neuropsychopharmacology: Update 2017. Pharmacopsychiatry. 2018 Jan; 51(1-02):9-62.

52 Dobrinas M, Cornuz J, Oneda B, Kohler Serra $M$, Puhl M, Eap CB. Impact of smoking, smoking cessation, and genetic polymorphisms on CYP1A2 activity and inducibility. Clin Pharmacol Ther. 2011 Jul;90(1):117-25.

53 de Leon J, Armstrong SC, Cozza KL. The dosing of atypical antipsychotics. Psychosomatics. 2005 May-Jun;46(3):262-73.

54 Ruan CJ, de Leon I. Is there a future for CYP1A2 pharmacogenetics in the optimal dosing of clozapine? Pharmacogenetics. doi: 10.2217/pgs-2020-0015.

55 Spina E, Hiemke C, de Leon J. Assessing drugdrug interactions through therapeutic drug monitoring when administering oral secondgeneration antipsychotics. Expert Opin Drug Metab Toxicol. 2016;12(4):407-22.

56 Andrade C. Delayed drug interactions in psychiatry: armodafinil and risperidone as a potential case in point. J Clin Psychiatry. 2015 Dec;76(12):1633-4

57 de Leon J. Future studies on the interaction between clozapine and valproic acid should aspire to include longitudinal designs and free valproate concentrations and should consider that inducer and/or inhibitory effects may vary with time, the individual and the autoinduction of valproic acid. Ther Drug Monit. 2020 Feb;42(1):159-61.

58 Schoretsanitis G, Kane JM, de Leon J. Adding oral contraceptives to clozapine may require halving the clozapine dose: a new case and a literature review. J Clin Psychopharmacol. Forthcoming 2020.

59 Odom-White A, de Leon J. Clozapine levels and caffeine. J Clin Psychiatry. 1996 Apr; 57(4):175-6.

60 Pinninti NR, de Leon J. Interaction of sertraline with clozapine. J Clin Psychopharmacol. 1997 Apr;17(2):119-20.

61 Cooke C, de Leon J. Adding other antipsychotics to clozapine. J Clin Psychiatry. 1999 Oct;60(10):710.

62 Wagner X, Kluge M. Abrupt decrease of clozapine plasma concentration after discontinuation of flupentixol comedication. J Clin Psychopharmacol. 2019 Mar/Apr;39(2):1689.

63 Barclay J, McCollum B, Schoretsanitis G, de Leon J. Gemfibrozil may decrease norclozapine elimination: a case report. J Clin Psychopharmacol. 2019 Jul/Aug;39(4):405-7.
64 Diaz FJ, Santoro V, Spina E, Cogollo M, Rivera TE, Botts $S$, et al. Estimating the size of the effects of co-medications on plasma clozapine concentrations using a model that controls for clozapine doses and confounding variables. Pharmacopsychiatry. 2008 May; 41(3):81-91.

65 Ruan CJ, Zang YN, Cheng YH, Wang CY, de Leon J. Around 3\% of 1,300 Levels Were Elevated during Infections in a Retrospective Review of 131 Beijing Hospital In-Patients with More than 24,000 Days of Clozapine Treatment. Psychother Psychosom. 2020 Feb;1-3. doi: 10.1159/000506355. [Epub ahead of print].

66 Verdoux H, Quiles C, de Leon J. Clinical determinants of fever in clozapine users and implications for treatment management: A narrative review. Schizophr Res. 2019 Sep;211: $1-9$.

67 Tracy TS, Venkataramanan R, Glover DD, Caritis SN; National Institute for Child Health and Human Development Network of Maternal-Fetal-Medicine Units. Temporal changes in drug metabolism (CYP1A2, CYP2D6 and CYP3A Activity) during pregnancy. Am J Obstet Gynecol. 2005 Feb;192(2):633-9.

68 Schoretsanitis G, Kane JM, Ruan CJ, Spina E, Hiemke C, de Leon J. A comprehensive review of the clinical utility of and a combined analysis of the clozapine/norclozapine ratio in therapeutic drug monitoring for adult patients. Expert Rev Clin Pharmacol. 2019 Jul; 12(7):603-21

69 de Leon J, Schoretsanitis G, Kane JM, Ruan CJ. Using therapeutic drug monitoring to personalize clozapine dosing in Asians. Asia Pac Psychiatry. 2020 Mar;e12384. doi: 10.1111/appy.12384. [Epub ahead of print]

70 Procyshyn RM, Vila-Rodriguez F, Honer WG, Barr AM. Clozapine administered once versus twice daily: does it make a difference? Med Hypotheses. 2014 Feb;82(2):225-8.

71 Procyshyn RM, Kennedy NB, Marriage S, Wasan KM. Plasma protein and lipoprotein distribution of clozapine. Am J Psychiatry. 2001 Jun;158(6):949-51.

72 Procyshyn RM, Ho T, Wasan KM. Competitive displacement of clozapine from plasma proteins in normolipidemic and hyperlipidemic plasma samples: clinical implications. Drug Dev Ind Pharm. 2005 May;31(4-5):3317.

73 Fang J, Mosier KE. Literature values of terminal half-lives of clozapine are dependent on the time of the last data point. J Pharm Pharm Sci. 2014;17(2):187-9.

74 de Leon J, Henighan V, Stanilla JK, Simpson GM. Clozapine levels after clozapine discontinuation. J Clin Psychopharmacol. 1996 Apr; 16(2):193-4.

75 Bauer LA. Clinical pharmacokinetics handbook. New York (NY): McGraw-Hill; 2006.
76 Jerling M, Lindström L, Bondesson U, Bertilsson L. Fluvoxamine inhibition and carbamazepine induction of the metabolism of clozapine: evidence from a therapeutic drug monitoring service. Ther Drug Monit. 1994 Aug; 16(4):368-74.

77 Couchman L, Morgan PE, Spencer EP, Johnston A, Flanagan RJ. Plasma clozapine and norclozapine in patients prescribed different brands of clozapine (Clozaril, Denzapine, and Zaponex). Ther Drug Monit. 2010 Oct;32(5): 624-7.

78 Couchman L, Morgan PE, Spencer EP, Flanagan RJ. Plasma clozapine, norclozapine, and the clozapine:norclozapine ratio in relation to prescribed dose and other factors: data from a therapeutic drug monitoring service, 1993 2007. Ther Drug Monit. 2010 Aug;32(4):43847.

79 Diaz FJ, de Leon J, Josiassen RC, Cooper TB, Simpson GM. Plasma clozapine concentration coefficients of variation in a long-term study. Schizophr Res. 2005 Jan;72(2-3):1315.

80 Palego L, Biondi L, Giannaccini G, Sarno N, Elmi S, Ciapparelli A, et al. Clozapine, norclozapine plasma levels, their sum and ratio in 50 psychotic patients: influence of patient-related variables. Prog Neuropsychopharmacol Biol Psychiatry. 2002 Apr;26(3):473-80.

81 Perry PJ, Miller DD, Arndt SV, Cadoret RJ. Clozapine and norclozapine plasma concentrations and clinical response of treatmentrefractory schizophrenic patients. Am J Psychiatry. 1991 Feb;148(2):231-5.

82 VanderZwaag C, McGee M, McEvoy JP, Freudenreich O, Wilson WH, Cooper TB. Response of patients with treatment-refractory schizophrenia to clozapine within three serum level ranges. Am J Psychiatry. 1996 Dec; 153(12):1579-84.

83 Wohkittel C, Gerlach M, Taurines R Wewetzer C, Unterecker S, Burger R, et al. Relationship between clozapine dose, serum concentration, and clinical outcome in children and adolescents in clinical practice. J Neural Transm (Vienna). 2016 Aug;123(8): 1021-31.

84 Patnaik RN, Lesko LJ, Chen ML, Williams RL; FDA Individual Bioequivalence Working Group. Individual bioequivalence. New concepts in the statistical assessment of bioequivalence metrics. Clin Pharmacokinet. 1997 Jul; 33(1):1-6.

85 Williams RL. FDA position on product selection for 'narrow therapeutic index' drugs. Am J Health Syst Pharm. 1997 Jul;54(14):1630-2.

86 de Leon J, Diaz FJ, Josiassen RC, Cooper TB, Simpson GM. Does clozapine decrease smoking? Prog Neuropsychopharmacol Biol Psychiatry. 2005 Jun;29(5):757-62.

87 Riesselman A, Strobl B, Cooley AT, de Leon J. A case report that suggested that aspirin's effects on valproic acid metabolism may contribute to valproic acid's inducer effects on clozapine metabolism. J Clin Psychopharmacol. 2013 Dec;33(6):812-4. 
88 Ruan CJ, de Leon J. Thirty years of both ignorance and clinical experience suggest that clozapine intoxication during co-occurring infections and inflammation may have higher morbidity and mortality than is currently believed. Psychosomatics. 2019 Mar - Apr; 60(2):221-2.

89 Ruan CJ, Zhen XY, Ge XL, Wang CY, Guo $\mathrm{W}$, Tang YL, et al. Pneumonia can cause clozapine intoxication: a case report. Psychosomatics. 2017 Nov - Dec;58(6):652-6.

90 Ruan CJ, Zhang XL, Guo W, Li WB, Zhuang HY, Li YQ, et al. Two cases of high serum clozapine concentrations occurring during inflammation in Chinese patients. Int J Psychiatry Med. 2018 Jul;53(4):292-305.

91 Bilbily J, McCollum B, de Leon J. Catatonia secondary to sudden clozapine withdrawal: a case with three repeated episodes and a literature review. Case Rep Psychiatry. 2017; 2017:2402731.

92 Buur-Rasmussen B, Brøsen K. Cytochrome P450 and therapeutic drug monitoring with respect to clozapine. Eur Neuropsychopharmacol. 1999 Dec;9(6):453-9.

93 Greenwood-Smith C, Lubman DI, Castle DJ. Serum clozapine levels: a review of their clinical utility. J Psychopharmacol. 2003 Jun; 17(2):234-8

94 Olesen OV. Therapeutic drug monitoring of clozapine treatment. Therapeutic threshold value for serum clozapine concentrations. Clin Pharmacokinet. 1998 Jun;34(6):497502.

95 Gaertner I, Gaertner HJ, Vonthein R, Dietz K. Therapeutic drug monitoring of clozapine in relapse prevention: a five-year prospective study. J Clin Psychopharmacol. 2001 Jun;21(3):305-10.

96 Stieffenhofer V, Saglam H, Schmidtmann I, Silver H, Hiemke C, Konrad A. Clozapine plasma level monitoring for prediction of rehospitalization schizophrenic outpatients. Pharmacopsychiatry. 2011 Mar;44(2):55-9.

97 Xiang YQ, Zhang ZJ, Weng YZ, Zhai YM, Li WB, Cai ZJ, et al. Serum concentrations of clozapine and norclozapine in the prediction of relapse of patients with schizophrenia. Schizophr Res. 2006 Apr;83(2-3):20110

98 Ulrich S, Wolf R, Staedt J. Serum level of clozapine and relapse. Ther Drug Monit. 2003 Apr;25(2):252-5.

99 Ulrich S, Baumann B, Wolf R, Lehmann D, Peters B, Bogerts B, et al. Therapeutic drug monitoring of clozapine and relapse- - a retrospective study of routine clinical data. Int J Clin Pharmacol Ther. 2003 Jan;41(1):3-13.

100 Fava GA, Tomba E, Bech P. Clinical pharmacopsychology: conceptual foundations and emerging tasks. Psychother Psychosom. 2017;86(3):134-40.

101 De Las Cuevas C, de Leon J. Reviving research on medication attitudes for improving pharmacotherapy: focusing on adherence. Psychother Psychosom. 2017;86(2): 73-9.
102 de Leon J, De Las Cuevas C. The art of pharmacotherapy: reflections on pharmacophobia. J Clin Psychopharmacol. 2017 Apr; 37(2):131-7.

103 McCutcheon R, Beck K, Bloomfield MA, Marques TR, Rogdaki M, Howes OD. Treatment resistant or resistant to treatment? Antipsychotic plasma levels in patients with poorly controlled psychotic symptoms. J Psychopharmacol. 2015 Aug;29(8):892-7.

104 McCutcheon R, Beck K, D'Ambrosio E, Donocik J, Gobjila C, Jauhar S, et al. Antipsychotic plasma levels in the assessment of poor treatment response in schizophrenia. Acta Psychiatr Scand. 2018 Jan;137(1):3946.

105 De Las Cuevas C, de Leon J. Development and validation of the Patient's Health Belief Questionnaire on Psychiatric Treatment. Patient Prefer Adherence. 2019 Apr;13:52736.

106 Howes OD, McCutcheon R, Agid O, de Bartolomeis A, van Beveren NJ, Birnbaum ML, et al. Treatment-Resistant Schizophrenia: Treatment Response and Resistance in Psychosis (TRRIP) Working Group Consensus Guidelines on Diagnosis and Terminology. Am J Psychiatry. 2017 Mar;174(3):216-29.

107 Kane JM, Correll CU. The role of clozapine in treatment-resistant schizophrenia. JAMA Psychiatry. 2016 Mar;73(3):187-8.

108 Taylor DM. Clozapine for treatment-resistant schizophrenia: still the gold standard? CNS Drugs. 2017 Mar;31(3):177-80.

109 Molent C, Olivo D, Wolf RC, Balestrieri M, Sambataro F. Functional neuroimaging in treatment resistant schizophrenia: A systematic review. Neurosci Biobehav Rev. 2019 Sep;104:178-90.

110 Leung CC, Gadelrab R, Ntephe CU, McGuire PK, Demjaha A. Clinical course, neurobiology and therapeutic approaches to treatment resistant schizophrenia. Toward an integrated view. Front Psychiatry. 2019 Sep;10:601.

111 Kennedy JL, Altar CA, Taylor DL, Degtiar I, Hornberger JC. The social and economic burden of treatment-resistant schizophrenia: a systematic literature review. Int Clin Psychopharmacol. 2014 Mar;29(2):63-76.

112 Hjorthøj C, Stürup AE, McGrath JJ, Nordentoft $M$. Years of potential life lost and life expectancy in schizophrenia: a systematic review and meta-analysis. Lancet Psychiatry. 2017 Apr;4(4):295-301.

113 Torniainen M, Mittendorfer-Rutz E, Tanskanen A, Björkenstam C, Suvisaari J, Alexanderson $\mathrm{K}$, et al. Antipsychotic treatment and mortality in schizophrenia. Schizophr Bull. 2015 May;41(3):656-63.

114 Vermeulen JM, van Rooijen G, van de Kerkhof MP, Sutterland AL, Correll CU, de Haan L. Clozapine and long-term mortality risk in patients with schizophrenia: a systematic review and meta-analysis of studies lasting 1.112.5 years. Schizophr Bull. 2019 Mar;45(2): 315-29.
115 Taipale H, Tanskanen A, Mehtälä J, Vattulainen P, Correll CU, Tiihonen J. 20-year follow-up study of physical morbidity and mortality in relationship to antipsychotic treatment in a nationwide cohort of 62,250 patients with schizophrenia (FIN20). World Psychiatry. 2020 Feb;19(1):61-8.

116 Cho J, Hayes RD, Jewell A, Kadra G, Shetty $\mathrm{H}$, MacCabe JH, et al. Clozapine and allcause mortality in treatment-resistant schizophrenia: a historical cohort study. Acta Psychiatr Scand. 2019 Mar;139(3):23747.

117 de Leon J, Stephens DB. Pathophysiology and clinical trials have limitations in some areas of medicine: focus on psychiatry (letter commenting: J Clin Epidemiol. 2014;67(4): 361-363.). J Clin Epidemiol. 2016 Jul;75: $126-7$.

118 Feinstein AR. Meta-analysis: statistical alchemy for the 21st century. J Clin Epidemiol. 1995 Jan;48(1):71-9.

119 Yildiz A, Vieta E, Correll CU, Nikodem M, Baldessarini RJ. Critical issues on the use of network meta-analysis in psychiatry. Harv Rev Psychiatry. 2014 Nov-Dec;22(6):36772.

120 Siskind D, McCartney L, Goldschlager R, Kisely S. Clozapine v. first- and second-generation antipsychotics in treatment-refractory schizophrenia: systematic review and meta-analysis. Br J Psychiatry. 2016 Nov; 209(5):385-92.

121 Siskind D, Siskind V, Kisely S. Clozapine response rates among people with treatmentresistant schizophrenia: data from a systematic review and meta-analysis. Can J Psychiatry. 2017 Nov;62(11):772-7.

122 Samara MT, Dold M, Gianatsi M, Nikolakopoulou A, Helfer B, Salanti G, et al. Efficacy, acceptability, and tolerability of antipsychotics in treatment-resistant schizophrenia: a network meta-analysis. JAMA Psychiatry. 2016 Mar;73(3):199-210.

123 Huhn M, Nikolakopoulou A, SchneiderThoma J, Krause M, Samara M, Peter N, et al. Comparative efficacy and tolerability of 32 oral antipsychotics for the acute treatment of adults with multi-episode schizophrenia: a systematic review and network meta-analysis. Lancet. 2019 Sep;394(10202): 939-51.

124 Mustafa FA. Use of clozapine in schizophrenia. JAMA Psychiatry. 2016 Oct;73(10): 1097.

125 McEvoy JP. Use of clozapine in schizophrenia. JAMA Psychiatry. 2016 Oct;73(10): 1097-8.

126 Fava GA. Evidence-based medicine was bound to fail: a report to Alvan Feinstein. Clin Epidemiol. 2017 Apr;84:3-7.

127 Land R, Siskind D, McArdle P, Kisely S, Winckel K, Hollingworth SA. The impact of clozapine on hospital use: a systematic review and meta-analysis. Acta Psychiatr Scand. 2017 Apr;135(4):296-309.

de Leon/Ruan/Schoretsanitis/

De las Cuevas 
128 Masuda T, Misawa F, Takase M, Kane JM, Correll CU. Association with hospitalization and all-cause discontinuation among patients with schizophrenia on clozapine vs other oral second-generation antipsychotics: a systematic review and meta-analysis of cohort studies. JAMA Psychiatry. 2019 Jul; 76(10):1052.

129 Fava GA, Guidi J. The pursuit of euthymia. World Psychiatry. 2020 Feb;19(1):40-50.

130 Van Putten T, Marder SR. Behavioral toxicity of antipsychotic drugs. J Clin Psychiatry. 1987 Sep;48 Suppl:13-9.

131 Fava GA, Cosci F, Offidani E, Guidi J. Behavioral toxicity revisited: iatrogenic comorbidity in psychiatric evaluation and treatment. J Clin Psychopharmacol. 2016 Dec;36(6):550-3.

132 Fava GA, Rafanelli C. Iatrogenic factors in psychopathology. Psychother Psychosom. 2019;88(3):129-40.

133 Leucht S, Cipriani A, Spineli L, Mavridis D, Orey D, Richter F, et al. Comparative efficacy and tolerability of 15 antipsychotic drugs in schizophrenia: a multiple-treatments meta-analysis. Lancet. 2013 Sep; 382(9896):951-62.

134 Hazari N, Kate N, Grover S. Clozapine and tardive movement disorders: a review. Asian J Psychiatr. 2013 Dec;6(6):439-51.

135 Weiden PJ. EPS profiles: the atypical antipsychotics are not all the same. J Psychiatr Pract. 2007 Jan;13(1):13-24.

136 Kane JM, Fleischhacker WW, Hansen L, Perlis R, Pikalov A 3rd, Assunção-Talbott S. Akathisia: an updated review focusing on second-generation antipsychotics. J Clin Psychiatry. 2009 Apr;70(5):627-43.

137 Levin H, Chengappa KN, Kambhampati RK, Mahdavi N, Ganguli R. Should chronic treatment-refractory akathisia be an indication for the use of clozapine in schizophrenic patients? J Clin Psychiatry. 1992 Jul;53(7): 248-51.

138 de Leon J, Moral L, Camuñas C. Clozapine and jaw dyskinesia: a case report. J Clin Psychiatry. 1991 Dec;52(12):494-5.

139 Mentzel TQ, van der Snoek R, Lieverse R, Oorschot M, Viechtbauer W, Bloemen O, et al. Clozapine monotherapy as a treatment for antipsychotic-induced tardive dyskinesia: a meta-analysis. J Clin Psychiatry. 2018 Sep;79(6):17r11852.

140 Pardis P, Remington G, Panda R, Lemez M, Agid O. Clozapine and tardive dyskinesia in patients with schizophrenia: A systematic review. J Psychopharmacol. 2019 Oct; 33(10):1187-98.

141 Lee D, Baek JH, Bae M, Choi Y, Hong KS. Long-term response to clozapine and its clinical correlates in the treatment of tardive movement syndromes: a naturalistic observational study in patients with psychotic disorders. J Clin Psychopharmacol. 2019 Nov/ Dec;39(6):591-6.
142 Caroff SN. Overcoming barriers to effective management of tardive dyskinesia. Neuropsychiatr Dis Treat. 2019 Apr;15:785-94.

143 Faay MD, Czobor P, Sommer IE. Efficacy of typical and atypical antipsychotic medication on hostility in patients with psychosisspectrum disorders: a review and meta-analysis. Neuropsychopharmacology. 2018 Nov; 43(12):2340-9.

144 Citrome L, Volavka J. The psychopharmacology of violence: making sensible decisions. CNS Spectr. 2014 Oct;19(5):411-8.

145 Lindström LH. Long-term clinical and social outcome studies in schizophrenia in relation to the cognitive and emotional side effects of antipsychotic drugs. Acta Psychiatr Scand Suppl. 1994;380 s380:74-6.

146 Weiden P, Aquila R, Standard J. Atypical antipsychotic drugs and long-term outcome in schizophrenia. J Clin Psychiatry. 1996;57 Suppl 11:53-60.

147 Stahl SM. “Awakening” from schizophrenia: intramolecular polypharmacy and the atypical antipsychotics. J Clin Psychiatry. 1997 Sep;58(9):381-2.

148 Nielsen J, Young C, Ifteni P, Kishimoto T, Xiang YT, Schulte PF, et al. Worldwide differences in regulations of clozapine use. CNS Drugs. 2016 Feb;30(2):149-61.

149 Rajagopal S. Clozapine, agranulocytosis, and benign ethnic neutropenia. Postgrad Med J. 2005 Sep;81(959):545-6.

150 Kelly DL, Kreyenbuhl J, Dixon L, Love RC, Medoff D, Conley RR. Clozapine underutilization and discontinuation in African Americans due to leucopenia. Schizophr Bull. 2007 Sep;33(5):1221-4.

151 Wiciński M, Węclewicz MM. Clozapine-induced agranulocytosis/granulocytopenia: mechanisms and monitoring. Curr Opin Hematol. 2018 Jan;25(1):22-8.

152 Myles N, Myles H, Xia S, Large M, Kisely S, Galletly C, et al. Meta-analysis examining the epidemiology of clozapine-associated neutropenia. Acta Psychiatr Scand. 2018 Aug;138(2):101-9.

153 Li XH, Zhong XM, Lu L, Zheng W, Wang SB, Rao WW, et al. The prevalence of agranulocytosis and related death in clozapinetreated patients: a comprehensive metaanalysis of observational studies. Psychol Med. 2020 Mar;50(4):583-94.

154 Legge SE, Hamshere ML, Ripke S, Pardinas AF, Goldstein JI, Rees E, et al.; ClozapineInduced Agranulocytosis Consortium. Genome-wide common and rare variant analysis provides novel insights into clozapineassociated neutropenia. Mol Psychiatry. 2017 Oct;22(10):1502-8.

155 de Leon J, Arranz MJ, Ruaño G. Pharmacogenetic testing in psychiatry: a review of features and clinical realities. Clin Lab Med. 2008 Dec;28(4):599-617.
156 Pfuhlmann B, Hiemke C, Unterecker S, Burger R, Schmidtke A, Riederer P, et al. Toxic clozapine serum levels during inflammatory reactions. J Clin Psychopharmacol. 2009 Aug;29(4):392-4.

157 Rohde C, Siskind D, de Leon J, Nielsen J. Antipsychotic medication exposure, clozapine, and pneumonia: results from a self-controlled study. Acta Psychiatr Scand. 2019 Dec 25. doi: 10.1111/acps.13142. [Epub ahead of print].

158 Walker AM, Lanza LL, Arellano F, Rothman KJ. Mortality in current and former users of clozapine. Epidemiology. 1997 Nov;8(6): 671-7.

159 Taylor DM, Douglas-Hall P, Olofinjana B, Whiskey E, Thomas A. Reasons for discontinuing clozapine: matched, case-control comparison with risperidone long-acting injection. Br J Psychiatry. 2009 Feb;194(2): 165-7.

160 Mustafa FA, Burke JG, Abukmeil SS, Scanlon JJ, Cox M. "Schizophrenia past clozapine": reasons for clozapine discontinuation, mortality, and alternative antipsychotic prescribing. Pharmacopsychiatry. 2015 Jan; 48(1):11-4.

161 de Leon J, Sanz EJ, Norén GN, De Las Cuevas $\mathrm{C}$. Pneumonia may be more frequent and have more fatal outcomes with clozapine than with other second-generation antipsychotics. World Psychiatry. 2020 Feb; 19(1):120-1.

162 de Leon J, Ruan CJ, Verdoux H, Wang CY Clinical relevance of the multifaceted relationship between clozapine and inflammation. Gen Psychiatr. Forthcoming 2020.

163 Landry P, Deschamps R, Tanguay N, Tessier S. Clozapine and tuberculosis. Psychosomatics. 2000 Nov-Dec;41(6):539-40.

164 Liu HC, Hung GC, Yang SY, Liao YT, Pan $\mathrm{CH}$, Chen $\mathrm{CC}$, et al. Antipsychotic drugs and risk of newly diagnosed tuberculosis in schizophrenia. Psychiatry Clin Neurosci. 2018 Oct;72(10):789-800.

165 Landry P, Benaliouad F, Tessier S. Increased use of antibiotics in clozapine-treated patients. Int Clin Psychopharmacol. 2003 Sep; 18(5):297-8.

166 Nielsen J, Foldager L, Meyer JM. Increased use of antibiotics in patients treated with clozapine. Eur Neuropsychopharmacol. 2009 Jul;19(7):483-6.

167 Ponsford M, Castle D, Tahir T, Robinson R Wade W, Steven R, et al. Clozapine is associated with secondary antibody deficiency. $\mathrm{Br}$ J Psychiatry. 2018 Sep;214:1-7.

168 Song C, Lin A, Kenis G, Bosmans E, Maes M Immunosuppressive effects of clozapine and haloperidol: enhanced production of the interleukin-1 receptor antagonist. Schizophr Res. 2000 Apr;42(2):157-64.

169 Cicala G, Barbieri MA, Spina E, de Leon J. A comprehensive review of swallowing difficulties and dysphagia associated with antipsychotics in adults. Expert Rev Clin Pharmacol. 2019 Mar;12(3):219-34. 
170 Sagy R, Weizman A, Katz N. Pharmacologi$\mathrm{cal}$ and behavioral management of some often-overlooked clozapine-induced side effects. Int Clin Psychopharmacol. 2014 Nov; 29(6):313-7.

171 Meyer JM, Stahl SM. The Clozapine Handbook: Stahl's Handbooks. Cambridge, UK: Cambridge University Press; 2019.

172 Papola D, Ostuzzi G, Gastaldon C, Morgano GP, Dragioti E, Carvalho AF, et al. Antipsychotic use and risk of life-threatening medical events: umbrella review of observational studies. Acta Psychiatr Scand. 2019 Sep; 140(3):227-43.

173 Siskind D, Sidhu A, Cross J, Chua YT, Myles $\mathrm{N}$, Cohen D, et al. Systematic review and meta-analysis of rates of clozapine-associated myocarditis and cardiomyopathy. Aust N Z J Psychiatry. 2020 Jan 20:4867419898760. doi: 10.1177/0004867419898760. [Epub ahead of print].

174 Brodie MJ. Lamotrigine. Lancet. 1992 Jun; 339(8806):1397-400.

175 Wong IC, Mawer GE, Sander JW. Factors influencing the incidence of lamotrigine-related skin rash. Ann Pharmacother. 1999 Oct; 33(10):1037-42.

176 Wang XQ, Lv B, Wang HF, Zhang X, Yu SY, Huang XS, et al. Lamotrigine-induced severe cutaneous adverse reaction: update data from 1999-2014. J Clin Neurosci. 2015 Jun; 22(6):1005-11.

177 Godhwani N, Bahna SL. Antiepilepsy drugs and the immune system. Ann Allergy Asthma Immunol. 2016 Dec;117(6):634-40.

178 Ronaldson KJ, Fitzgerald PB, Taylor AJ, Topliss DJ, McNeil JJ. A new monitoring protocol for clozapine-induced myocarditis based on an analysis of 75 cases and 94 controls. Aust N Z J Psychiatry. 2011 Jun;45(6): 458-65.

179 Ronaldson KJ. Cardiovascular disease in clozapine-treated patients: evidence, mechanisms and management. CNS Drugs. 2017 Sep;31(9):777-95.

180 Taskent RO, Gokcumen O. The multiple histories of Western Asia: perspectives from ancient and modern genomes. Hum Biol. 2017 Apr;89(2):107-17.

181 Higgins JM, San C, Lagnado G, Chua D, Mihic $\mathrm{T}$. Incidence and management of clozapine-induced myocarditis in a large tertiary hospital. Can J Psychiatry. 2019 Aug;64(8): 561-7.

182 Neufeld NH, Remington G. Clozapine-induced myocarditis in Canada: evidence from spontaneous reports. Schizophr Res. 2019 Apr;206:462-3.

183 Chopra N, de Leon J. Clozapine-induced myocarditis may be associated with rapid titration: A case report verified with autopsy. Int J Psychiatry Med. 2016;51(1):104-15.

184 Cook SC, Ferguson BA, Cotes RO, Heinrich TW, Schwartz AC. Clozapine-induced myocarditis: prevention and considerations in rechallenge. Psychosomatics. 2015 NovDec;56(6):685-90.
185 Anıl Yağcioğlu AE, Ertuğrul A, Karakaşlı AA, Ağaoğlu E, Ak S, Karahan S, et al. A comparative study of detection of myocarditis induced by clozapine: with and without cardiac monitoring. Psychiatry Res. 2019 Sep;279:90-7.

186 Jahołkowski P, Niewiadomska J, Wciórka J, Kowalski M, Świtaj P. Clozapine-induced myocarditis during co-administration of valproate: A case report. Psychiatr Pol. 2019 Oct;53(5):997-1002.

187 Otsuka Y, Idemoto K, Hosoda Y, Imamura Y, Aoki T. Clozapine-induced myocarditis: follow-up for 3.5 years after successful retrial. J Gen Fam Med. 2019 Feb;20(3):114-7.

188 Palmer SE, McLean RM, Ellis PM, HarrisonWoolrych M. Life-threatening clozapine-induced gastrointestinal hypomotility: an analysis of 102 cases. J Clin Psychiatry. 2008 May;69(5):759-68.

189 FDA. FDA strengthens warning that untreated constipation caused by schizophrenia medicine clozapine (Clozaril) can lead to serious bowel problems [Internet] [accessed 2020 Feb 23]. Available from: https://www. fda.gov/drugs/drug-safety-and-availability/ fda-strengthens-warning-untreated-constipation-caused-schizophrenia-medicineclozapine-clozaril-can.

190 Every-Palmer S, Ellis PM. Clozapine-induced gastrointestinal hypomotility: a $22-$ year bi-national pharmacovigilance study of serious or fatal 'slow gut' reactions, and comparison with international drug safety advice. CNS Drugs. 2017 Aug;31(8):699709.

191 Shirazi A, Stubbs B, Gomez L, Moore S, Gaughran F, Flanagan RJ, et al. Prevalence and predictors of clozapine-associated constipation: a systematic review and metaanalysis. Int J Mol Sci. 2016 Jun;17(6):E863.

192 Every-Palmer S, Newton-Howes G, Clarke MJ. Pharmacological treatment for antipsychotic-related constipation. Cochrane Database Syst Rev. 2017 Jan;1:CD011128.

193 Every-Palmer S, Ellis PM, Nowitz M, Stanley J, Grant E, Huthwaite M, et al. The Porirua protocol in the treatment of clozapine-induced gastrointestinal hypomotility and constipation: a pre- and post-treatment study. CNS Drugs. 2017 Jan;31(1):75-85.

194 Cohen D. Clozapine and gastrointestinal hypomotility. CNS Drugs. 2017 Dec;31(12): 1083-91.

195 Tie H, Walker BD, Singleton CB, Bursill JA, Wyse KR, Campbell TJ, et al. Clozapine and sudden death. J Clin Psychopharmacol. 2001 Dec;21(6):630-2.

196 Law D, Mohan T, Bastiampillai T, Dhillon R. Clozapine rechallenge following QTc prolongation. Aust N Z J Psychiatry. 2014 Feb; 48(2):198-9.
197 Kang UG, Kwon JS, Ahn YM, Chung SJ, Ha $\mathrm{JH}$, Koo YJ, et al. Electrocardiographic abnormalities in patients treated with clozapine. J Clin Psychiatry. 2000 Jun;61(6):441-6.

198 Grande I, Pons A, Baeza I, Torras Á, Bernardo M. QTc prolongation: is clozapine safe? Study of 82 cases before and after clozapine treatment. Hum Psychopharmacol. 2011 Aug;26(6):397-403.

199 Raschi E, Poluzzi E, Godman B, Koci A, Moretti U, Kalaba M, et al. Torsadogenic risk of antipsychotics: combining adverse event reports with drug utilization data across Europe. PLoS One. 2013 Nov 8(11):e81208.

200 Spina E, de Leon J. Clinically relevant interactions between newer antidepressants and second-generation antipsychotics. Expert Opin Drug Metab Toxicol. 2014 May;10(5): $721-46$.

201 de Leon J, Santoro V, D’Arrigo C, Spina E. Interactions between antiepileptics and second-generation antipsychotics. Expert Opin Drug Metab Toxicol. 2012 Mar;8(3):311-34.

202 Pacia SV, Devinsky O. Clozapine-related seizures: experience with 5,629 patients. Neurology. 1994 Dec;44(12):2247-9.

203 McCollum B, Barclay J, de Leon J. Unexpected falls during clozapine treatment explained by myoclonus. Prim Care Companion CNS Disord. 2018 Jan 18;20(1). pii: 17102151. doi: 10.4088/PCC.17102151.

204 Williams AM, Park SH. Seizure associated with clozapine: incidence, etiology, and management. CNS Drugs. 2015 Feb;29(2): 101-11.

205 Grover S, Hazari N, Chakrabarti S, Avasthi A. Association of clozapine with seizures: a brief report involving 222 patients prescribed clozapine. East Asian Arch Psychiatry. 2015 Jun;25(2):73-8.

206 Caetano D. Use of anticonvulsants as prophylaxis for seizures in patients on clozapine. Australas Psychiatry. 2014 Feb;22(1): $78-83$.

207 Sabaawi M, Singh NN, de Leon J. Guidelines for the use of clozapine in individuals with developmental disabilities. Res Dev Disabil. 2006 May-Jun;27(3):309-36.

208 de Leon J, Diaz FJ. Planning for the optimal design of studies to personalize antipsychotic prescriptions in the post-CATIE era: the clinical and pharmacoepidemiological data suggest that pursuing the pharmacogenetics of metabolic syndrome complications (hypertension, diabetes mellitus and hyperlipidemia) may be a reasonable strategy. Schizophr Res. 2007 Nov;96(1-3):185-97.

209 Leucht S, Leucht C, Huhn M, Chaimani A, Mavridis D, Helfer B, et al. Sixty years of placebo-controlled antipsychotic drug trials in acute schizophrenia: systematic review, Bayesian meta-analysis, and meta-regression of efficacy predictors. Am J Psychiatry. 2017 Oct;174(10):927-42. 
210 Kim DD, Barr AM, Lu C, Stewart SE, White RF, Honer WG, et al. Clozapine-associated obsessive-compulsive symptoms and their management: a systematic review and analysis of 107 reported cases. Psychother Psychosom. 2020 Feb 11:1-10. doi: 10.1159/000505876. [Epub ahead of print].

211 Chouinard G, Samaha AN, Chouinard VA, Peretti CS, Kanahara N, Takase M, et al. Antipsychotic-induced dopamine supersensitivity psychosis: pharmacology, criteria, and therapy. Psychother Psychosom. 2017; 86(4):189-219.

212 de Leon J, Stanilla JK, White AO, Simpson GM. Anticholinergics to treat clozapine withdrawal. J Clin Psychiatry. 1994 Mar; 55(3):119-20.

213 Stanilla JK, de Leon J, Simpson GM. Clozapine withdrawal resulting in delirium with psychosis: a report of three cases. J Clin Psychiatry. 1997 Jun;58(6):252-5.

214 Mustafa FA. Schizophrenia past clozapine: what works? J Clin Psychopharmacol. 2013 Feb;33(1):63-8.

215 Grassi B, Ferrari R, Epifani M, Dragoni C, Cohen S, Scarone S. Clozapine lacks previous clinical efficacy when restarted after a period of discontinuation: a case series. Eur Neuropsychopharmacol. 1999 Dec;9(6): 479-81.

216 Miodownik C, Lerner V, Kibari A, Toder D, Cohen $\mathrm{H}$. The effect of sudden clozapine discontinuation on management of schizophrenic patients: A retrospective controlled study. J Clin Psychiatry. 2006 Aug;67(8): 1204-8.

217 Bachmann CJ, Aagaard L, Bernardo M, Brandt L, Cartabia M, Clavenna A, et al. International trends in clozapine use: a study in 17 countries. Acta Psychiatr Scand. 2017 Jul;136(1):37-51.

218 Cetin M. Clozaphobia; fear of prescribers of clozapine for treatment of schizophrenia. Klinik Psikofarmakol Bülteni. 2014;24(4): 295-301.

219 Farooq S, Choudry A, Cohen D, Naeem F, Ayub M. Barriers to using clozapine in treatment-resistant schizophrenia: systematic review. BJPsych Bull. 2019 Feb;43(1):8-16.

220 Verdoux H, Quiles C, Bachmann CJ, Siskind D. Prescriber and institutional barriers and facilitators of clozapine use: A systematic review. Schizophr Res. 2018 Nov;201:10-9.

221 Knowles SA, Mcmillan SS, Wheeler AJ. Consumer access to clozapine in Australia: how does this compare to New Zealand and the United Kingdom? Pharm Pract (Granada). 2016 Apr-Jun;14(2):722.

222 Gee SH, Shergill SS, Taylor DM. Patient attitudes to clozapine initiation. Int Clin Psychopharmacol. 2017 Nov;32(6):337-42.

223 Netherlands clozapine collaboration group. Guideline for the Use of Clozapine [Internet] [accessed $2020 \mathrm{Feb} 23$ ]. Available from: http://www.clozapinepluswerkgroep.nl/ wp-content/uploads/2013/07/Guidelinefor-the-use-of-Clozapine-2013.pdf
224 Bogers JP, Schulte PF, Van Dijk D, Bakker B, Cohen D. Clozapine underutilization in the treatment of schizophrenia: how can clozapine prescription rates be improved? J Clin Psychopharmacol. 2016 Apr;36(2):109-11.

225 Wheeler A, Humberstone V, Robinson G. Outcomes for schizophrenia patients with clozapine treatment: how good does it get? J Psychopharmacol. 2009 Nov;23(8):957-65.

226 Preskorn SH. Comments on the role of therapeutic drug monitoring for clozapine. J Psychiatr Pract. 2005 Sep;11(5):340-3.

227 Schulte $\mathrm{P}$. What is an adequate trial with clozapine?: therapeutic drug monitoring and time to response in treatment-refractory schizophrenia. Clin Pharmacokinet. 2003; 42(7):607-18.

228 Lu ML, Lane HY, Lin SK, Chen KP, Chang WH. Adjunctive fluvoxamine inhibits clozapine-related weight gain and metabolic disturbances. J Clin Psychiatry. 2004 Jun; 65(6):766-71.

229 Bousman CA, Hopwood M. Commercial pharmacogenetic-based decision-support tools in psychiatry. Lancet Psychiatry. 2016 Jun;3(6):585-90.

230 de Leon J. Pharmacogenetic tests in psychiatry: from fear to failure to hype. J Clin Psychopharmacol. 2016 Aug;36(4):299-304.

231 de Leon J, Spina E. What is needed to incorporate clinical pharmacogenetic tests into the practice of psychopharmacotherapy? Expert Rev Clin Pharmacol. 2016;9(3):3514.

232 Bousman CA, Dunlop BW. Genotype, phenotype, and medication recommendation agreement among commercial pharmacogenetic-based decision support tools. Pharmacogenomics J. 2018 Sep;18(5):613-22.

233 Li KJ, Solomon HV, DeLisi LE. Clozapine pharmacogenomics: a review of efficacy, pharmacokinetics, and agranulocytosis. Curr Opin Psychiatry. 2018 Sep;31(5):4038.

$234 \mathrm{Na}$ Takuathung $\mathrm{M}$, Hanprasertpong N, Teekachunhatean S, Koonrungsesomboon $\mathrm{N}$. Impact of CYP1A2 genetic polymorphisms on pharmacokinetics of antipsychotic drugs: a systematic review and metaanalysis. Acta Psychiatr Scand. 2019 Jan; 139(1):15-25.

235 Kalaria SN, Kelly DL. Development of pointof-care testing devices to improve clozapine prescribing habits and patient outcomes. Neuropsychiatr Dis Treat. 2019 Aug; 15: 2365-70.

236 Bui HN, Bogers JP, Cohen D, Njo T, Herruer $\mathrm{MH}$. Evaluation of the performance of a point-of-care method for total and differential white blood cell count in clozapine users. Int J Lab Hematol. 2016 Dec;38(6):7039.

Psychother Psychosom 2020;89:200-214

DOI: $10.1159 / 000507638$
237 Winkler TE, Stevenson FO, Kim E, Kang M, Payne GF, Kelly DL, et al. The role of microsystems integration towards point-of-care clozapine treatment monitoring in schizophrenia. IEEE Sens Lett. 2018 Mar;2(1). pii 5500304. doi: 10.1109/LSENS.2017.2782883.

238 Geers LM, Cohen D, Wehkamp LM, van Hateren K, Koster RA, Fedorenko OY, et al. Dried blood spot analysis for therapeutic drug monitoring of clozapine. J Clin Psychiatry. 2017 Nov/Dec;78(9):e1211-8.

239 Nakahara T, Otani N, Ueno T, Hashimoto K. Development of a hematocrit-insensitive device to collect accurate volumes of dried blood spots without specialized skills for measuring clozapine and its metabolites as model analytes. J Chromatogr B Analyt Technol Biomed Life Sci. 2018 Jun;10871088:70-9.

240 Temesi D, Swales J, Keene W, Dick S. The stability of amitriptyline $\mathrm{N}$-oxide and clozapine $\mathrm{N}$-oxide on treated and untreated dry blood spot cards. J Pharm Biomed Anal. 2013 Mar;76:164-8.

241 Man WH, Pérez-Pitarch A, Wilting I, Heerdink ER, van Solinge WW, Egberts AC, et al. Development of a nomogram for the estimation of long-term adherence to clozapine therapy using neutrophil fluorescence. Br J Clin Pharmacol. 2018 Jun;84(6): 1228-37.

242 Xu SW, Dong M, Zhang Q, Yang SY, Chen LY, Sim K, et al. Clozapine prescription pattern in patients with schizophrenia in Asia: The REAP survey (2016). Psychiatry Res. 2019 Mar 15. pii: S0165-1781(18)32218-2.

243 Barber S, Olotu U, Corsi M, Cipriani A. Clozapine combined with different antipsychotic drugs for treatment-resistant schizophrenia. Cochrane Database Syst Rev. 2017 Mar;3:CD006324.

244 Zheng W, Xiang YT, Yang XH, Xiang YQ, de Leon J. Clozapine augmentation with antiepileptic drugs for treatment-resistant schizophrenia: a meta-analysis of randomized controlled trials. J Clin Psychiatry. 2017 May;78(5):e498-505.

245 Wang G, Zheng W, Li XB, Wang SB, Cai DB, Yang XH, et al. ECT augmentation of clozapine for clozapine-resistant schizophrenia: A meta-analysis of randomized controlled trials. J Psychiatr Res. 2018 Oct; 105 23-32.

246 Schoretsanitis G, Mendelowitz A, Malur C, Braga RJ, Schooler NR, John M, et al. Lack of ECT effects on clozapine plasma levels in patients with treatment-resistant schizophrenia: Pharmacokinetic evidence from a randomized clinical trial. Schizophr Res. 2020 Feb 24. pii: S0920-9964(20)30084-0.

247 Bai Z, Wang G, Cai S, Ding X, Liu W, Huang $\mathrm{D}$, et al. Efficacy, acceptability and tolerability of 8 atypical antipsychotics in Chinese patients with acute schizophrenia: A network meta-analysis. Schizophr Res. $2017 \mathrm{Jul}$; 185:73-9. 
248 Keating D, McWilliams S, Schneider I, Hynes C, Cousins G, Strawbridge J, et al. Pharmacological guidelines for schizophrenia: a systematic review and comparison of recommendations for the first episode. BMJ Open. 2017 Jan;7(1):e013881.

249 Krause M, Zhu Y, Huhn M, SchneiderThoma J, Bighelli I, Chaimani A, et al. Efficacy, acceptability, and tolerability of antipsychotics in children and adolescents with schizophrenia: A network meta-analysis. Eur Neuropsychopharmacol. 2018 Jun; 28(6):659-74.

250 Frogley C, Taylor D, Dickens G, Picchioni M. A systematic review of the evidence of clozapine's anti-aggressive effects. Int J Neuropsychopharmacol. 2012 Oct;15(9):135171.
251 Ma CH, Chang SS, Tsai HJ, Gau SS, Chen IM, Liao SC, et al. Comparative effect of antipsychotics on risk of self-harm among patients with schizophrenia. Acta Psychiatr Scand. 2018 Apr;137(4):296-305.

252 Krause M, Huhn M, Schneider-Thoma J, Bighelli I, Gutsmiedl K, Leucht S. Efficacy, acceptability and tolerability of antipsychotics in patients with schizophrenia and comorbid substance use. A systematic review and meta-analysis. Eur Neuropsychopharmacol. 2019 Jan;29(1):32-45.

253 Li XB, Tang YL, Wang CY, de Leon J. Clozapine for treatment-resistant bipolar disorder: a systematic review. Bipolar Disord. 2015 May; 17(3):235-47.

254 Verghese C, de Leon J, Josiassen RC. Problems and progress in the diagnosis and treatment of polydipsia and hyponatremia. Schizophr Bull. 1996;22(3):455-64.
255 Rohde C, Hilker R, Siskind D, Nielsen J. Real-world effectiveness of clozapine for intellectual disability: results from a mirrorimage and a reverse-mirror-image study. J Psychopharmacol. 2018 Nov;32(11):1197203.

256 Rohde C, Polcwiartek C, Correll CU, Nielsen J. Real-World Effectiveness of clozapine for borderline personality disorder: results from a 2-year mirror-image study. J Pers Disord. 2018 Dec;32(6):823-37.

257 Iketani R, Kawasaki Y, Yamada H. Comparative utility of atypical antipsychotics for the treatment of psychosis in Parkinson's Disease: a systematic review and Bayesian network meta-analysis. Biol Pharm Bull. 2017; 40(11):1976-82. 